\title{
Variations of Plasmid Content in Rickettsia felis
}

\author{
Pierre-Edouard Fournier ${ }^{1}$, Lokmane Belghazi ${ }^{1}$, Catherine Robert ${ }^{1}$, Khalid Elkarkouri ${ }^{1}$, Allen L. Richards ${ }^{2}$, \\ Gilbert Greub ${ }^{3}$, François Collyn ${ }^{3}$, Motohiko Ogawa ${ }^{4}$, Arantxa Portillo ${ }^{5}$, Jose A. Oteo ${ }^{5}$, Anna Psaroulaki ${ }^{6}$, \\ Idir Bitam ${ }^{7}$ Didier Raoult ${ }^{1 *}$
}

1 Unité des rickettsies, IFR 48, CNRS-IRD UMR 6236, Faculté de médecine, Université de la Méditerranée, Marseille, France, 2 Naval Medical Research Center, Silver Spring, Maryland, United States of America, 3 Center for Research on Intracellular Bacteria, Institute of Microbiology, University Hospital Center and University of Lausanne, Lausanne, Switzerland, 4 Department of Virology I, National Institute of Infectious Diseases, Tokyo, Japan, 5 Hospital San Pedro- Centro de Investigación Biomédica de La Rioja (CIBIR), Área de Enfermedades Infecciosas, Logroño, Spain, 6 Laboratory of Clinical Bacteriology, Parasitology, Zoonoses and Geographical Medicine, University of Crete, Heraklion, Crete, Greece, 7 Unité d'Entomologie Médiale, Service d'Eco-Epidémiologie Parasitaire, Institut Pasteur, Alger, Algeria

\begin{abstract}
Background: Since its first detection, characterization of $R$. felis has been a matter of debate, mostly due to the contamination of an initial $R$. felis culture by $R$. typhi. However, the first stable culture of $R$. felis allowed its precise phenotypic and genotypic characterization, and demonstrated that this species belonged to the spotted fever group rickettsiae. Later, its genome sequence revealed the presence of two forms of the same plasmid, physically confirmed by biological data. In a recent article, Gillespie et al. (PLoS One. 2007;2(3):e266.) used a bioinformatic approach to refute the presence of the second plasmid form, and proposed the creation of a specific phylogenetic group for $R$. felis.

Methodology/Principal Findings: In the present report, we, and five independent international laboratories confirmed unambiguously by PCR the presence of two plasmid forms in R. felis strain URRWXCal ${ }_{2}^{\top}$, but observed that the plasmid content of this species, from none to 2 plasmid forms, may depend on the culture passage history of the studied strain. We also demonstrated that $R$. felis does not cultivate in Vero cells at $37^{\circ} \mathrm{C}$ but generates plaques at $30^{\circ} \mathrm{C}$. Finally, using a phylogenetic study based on 667 concatenated core genes, we demonstrated the position of $R$. felis within the spotted fever group.
\end{abstract}

Significance: We demonstrated that $R$. felis, which unambiguously belongs to the spotted fever group rickettsiae, may contain up to two plasmid forms but this plasmid content is unstable.

Citation: Fournier P-E, Belghazi L, Robert C, Elkarkouri K, Richards AL, et al. (2008) Variations of Plasmid Content in Rickettsia felis. PLoS ONE 3(5): e2289. doi:10.1371/journal.pone.0002289

Editor: Christophe Herman, Baylor College of Medicine, United States of America

Received September 17, 2007; Accepted April 7, 2008; Published May 28, 2008

Copyright: (c) 2008 Fournier et al. This is an open-access article distributed under the terms of the Creative Commons Attribution License, which permits unrestricted use, distribution, and reproduction in any medium, provided the original author and source are credited.

Funding: The authors have no support or funding to declare.

Competing Interests: The authors have declared that no competing interests exist.

* E-mail: Didier.Raoult@gmail.com

\section{Introduction}

Rickettsia felis (R. felis) was first detected in 1990 in American Ctenocephalides felis fleas using electron microscopy, and named the ELB agent after the Elward laboratory (Soquel, CA) where the flea colony was raised [1]. It was later detected by PCR in humans with a murine typhus-like illness [2-6]. Unfortunately, despite a first phylogenetic study clearly showing its classification within the spotted fever group (SFG) [7], confusion was brought by further reports, which attributed to the ELB agent, renamed $R$. felis, several characteristics of $R$. typhi [8-11]. It was later demonstrated that these data, including the protein profile [11], antigenic properties, growth conditions [8,9], and antibiotic susceptibility [10], resulted from the contamination of a $R$. felis culture with $R$. typhi [12]. As a matter of fact, fleas can be infected by both $R$. typhi and $R$. felis [13], which may thus have been the source of contamination. In 2001, R. felis was cultivated from cat fleas at low temperature $\left(28^{\circ} \mathrm{C}\right)$, and was established for the first time [2]. It was then deposited as strain $\mathrm{URRWXCal}_{2}{ }^{\mathrm{T}}$ in two official collections: the American Type Culture Collection (ATGG VR-
1525), and the Collection de Souches de l'Unité des Rickettsies (CSUR R121). Subsequently, another two teams were able to successfully grow $R$. felis, also at temperatures $\leq 32^{\circ} \mathrm{C}[14,15]$ and not at $35-37^{\circ} \mathrm{C}$ as initially reported $[9,10,12]$. Phenotypic characterization of strain URRWXCal ${ }_{2}^{\mathrm{T}}$ demonstrated that its antibiotic susceptibility [16] and antigenic properties [17] classified it within the SFG. In 2005, we sequenced the genome of $R$. felis strain URRWXCal ${ }_{2}^{\mathrm{T}}$ [18] and demonstrated, using bioinformatics, pulsed field gel electrophoresis and southern blot, that this strain had two forms of the same plasmid, i. e., a large, (pRF, 62$\mathrm{kb})$, and a small (pRF $\delta, 39-\mathrm{kb})$ forms. The $\mathrm{pRF}$ and PRF $\delta$ plasmids had identical sequences with the exception of an additional $24 \mathrm{ORFs}$ in pRF. Then, we confirmed these results by PCR assays specifically targeting each plasmid [18]. The two plasmids were also detected in a collection of Ctenocephalides felis fleas from various locations. However, in a recent bioinformatic analysis of the $R$. felis genome sequence, Gillespie et al. questioned our results and proposed that the $\mathrm{pRF} \delta$ plasmid was an artefact from genome assembly [19]. These authors based in part their conclusion on the results from Pornwiroon et al. who failed to 


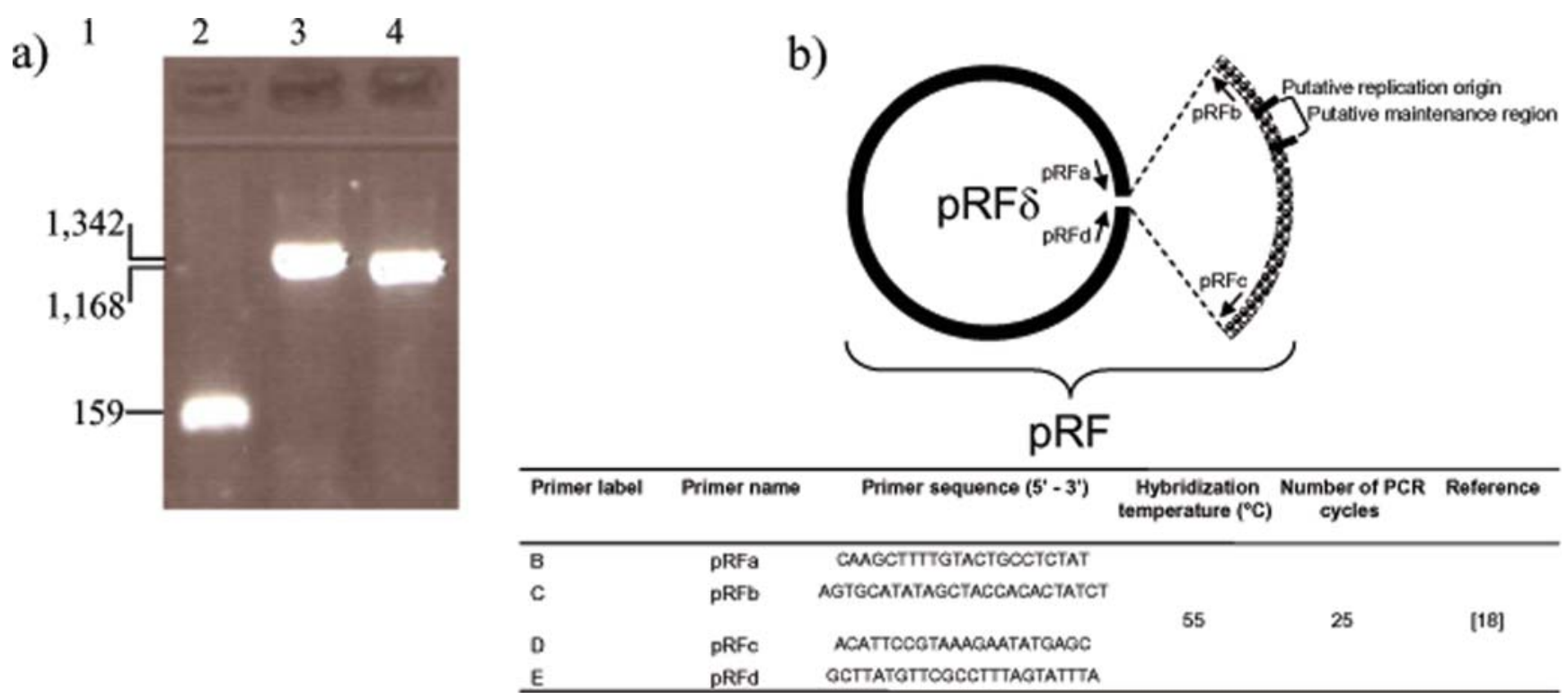

Figure 1. The $R$. felis plasmids. Specific PCR amplification of the two R. felis plasmid forms. Lane 1: Molecular size (bp); lane 2: pRFa-pRFb amplicon; lane 3: pRFc-pRFd amplicon; lane 4: pRFa-pRFd amplicon; b) Schematic representation of $R$. felis plasmids indicating the position of PCR primers used to amplify the pRF (pRFa/pRFb and pRFc/pRFd primer pairs) and pRF $\delta$ (pRFa/pRFd primer pair) plasmids. doi:10.1371/journal.pone.0002289.g001

detect the pRF $\delta$ plasmid in $R$. felis strain LSU [14], a strain cultivated in C. felis fleas at Louisiana State University [20]. In addition, on the basis of the analysis of a few genes, they proposed the classification of $R$. felis in a fourth phylogenetic lineage within the Rickettsia genus [19].

As our previous work had been carefully performed and experimentally confirmed, we believe that the conclusions of Gillespie et al. were not appropriate. Therefore, we asked five independent laboratories worldwide to check the presence of two plasmids in $R$. felis. We also evaluated the presence of both plasmids in various specimens and in cloned $R$. felis. Finally, we conducted a phylogenetic study based on 667 concatenated Rickettsia core protein-encoding genes, and tested new specimens.

\section{Results}

Presence of two plasmids in R. felis strain URRWXCal ${ }_{2}^{\top}$ and variation of plasmid content according to the passage history

Using all four primer pairs, we obtained PCR products of the expected sizes from $R$. felis cultivated from the initial isolate [2]. Non-template controls were negative. The sequence obtained from the pRFa-pRFd amplicon was identical to GenBank accession number NG_007111, whereas pRFa-pRFb and pRFcpRFd amplicons were identical to accession number NG_007110. Thus, we could reproduce our previously reported result and confirmed the presence of the two plasmids in $R$. felis strain $\mathrm{URRWXCal}_{2}{ }^{\mathrm{T}}$. However, in order to obtain indisputable results, we proposed five independent laboratories worldwide to perform these PCR assays. To avoid any interpretation bias, we provided these laboratories with anonymized kits. All five laboratories obtained similar PCR results (Figure la, Table 1). A PCR product of the expected size was obtained for all 4 assays from DNA specimen 1, whereas for DNA specimens 2 and 3, only the AF-AR PCR provided a positive amplification. Negative controls were negative for all assays. Each of the five laboratories obtained a B-E PCR nucleotide sequence for $R$. felis identical to GenBank accession number NC_007111. Sequences were deposited in GenBank under accession numbers EU155007, EU056172, EU022170, EU040362, and EU017504 for laboratories L1 to L5, respectively. Further, when attempting to clone $R$. felis cells with a 40 cell culture passage history at various temperatures using the plaque assay, we obtained lysis plaques at $30^{\circ} \mathrm{C}$ but no culture at $37^{\circ} \mathrm{C}$ (Figure 2). Of 20 clones grown from single $R$. felis cells and individually collected, we obtained PCR products of the expected sizes for the two plasmid forms in 15 clones (75\%) but only the large plasmid form in the remaining five clones. In addition, only the small plasmid form was detected from the positive control DNA extracted from $R$. felis with a 50 cell culture passage history. These data demonstrated that the plasmid content of $R$. felis may vary according to culture history, with a small plasmid form being unstable. $R$. felis may exhibit from two $(R$. felis grown from initial frozen culture) to one plasmid form $(R$. felis with a 50 cell culture passages). Such a phenomenon was recently reported by Baldridge et al. who demonstrated that $R$. peacockii lost its plasmids during serial passage in cell culture [21].

In their article, Gillespie et al. speculated, based on an in silico analysis, that the small plasmid form detected in $R$. felis was an artefact of genome assembly [19]. In our previous study, we were surprised to find two plasmid forms in R. felis, but found them both

Table 1. PCR results obtained by all five tester laboratories

\begin{tabular}{lllll}
\hline & & & \\
\hline $\begin{array}{l}\text { DNA specimen } \\
\text { (species) }\end{array}$ & \multicolumn{1}{l}{ PCR assay (primers) } & & \\
\cline { 2 - 5 } & $\begin{array}{l}\text { B-E } \\
\text { (pRFa-pRFd) }\end{array}$ & $\begin{array}{l}\text { B-C } \\
\text { (pRFa-pRFb) }\end{array}$ & $\begin{array}{l}\text { D-E } \\
\text { (pRFc-pRFd) }\end{array}$ & AF-AR \\
\hline DNA1 (R. felis) & + & + & + & + \\
DNA2 (R. conorii) & - & - & - & + \\
DNA3 (R. africae) & - & - & - & + \\
\hline
\end{tabular}

doi:10.1371/journal.pone.0002289.t001 


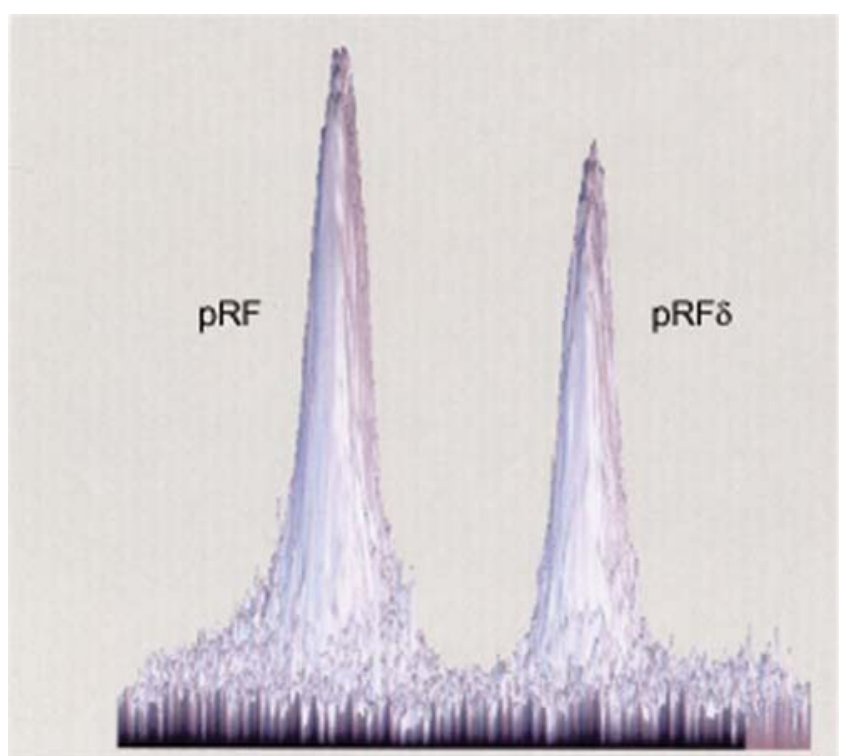

Figure 2. Cloning of $\boldsymbol{R}$. felis cells using a plaque assay. White arrows show individual lysis plaques. Right, a lysis plaque was enlarged. doi:10.1371/journal.pone.0002289.g002

by pulsed field gel electrophoresis (Figure 3), southern blot, and genome assembly [18]. Moreover, we verified biologically that the small plasmid form can specifically be amplified by PCR, showing that the 2 plasmid forms exist both in cell culture and in the wild by amplification of $R$. felis DNA from C. felis fleas [18]. Therefore, the results that we and five independent laboratories obtained in the present study unambiguously confirm that our previous data did not result from a bioinformatic error and that two plasmid forms may co-exist in $R$. felis (Figure 1b). Moreover, by demonstrating in gels that the two plasmid forms were present in almost equal quantity in culture, we speculated that both forms may be present in a single $R$. felis cell (Figure 3). To explore this hypothesis, we cloned single $R$. felis cells and demonstrated that the small plasmid form lacked in $25 \%$ of individual cells of this species. Baldridge et al. recently reported the detection of plasmids in five Rickettsia species, including two, i.e., $R$. peacockii and $R$. amblyommii which had two plasmids [21]. These results, as well as ours, contradict the speculations of Gillespie et al. [19] that $R$. felis cannot have two plasmids.

\section{Variation of plasmid content in $R$. felis according to the strain}

In addition to their bioinformatics analysis, Gillespie et al. based their conclusions on the results published by Pornwiroon et al. who did not detect the $\mathrm{pRF} \delta$ plasmid form from $R$. felis strain LSU [14]. In the present study, the expert laboratory L1 detected the pRF but not the pRF $\delta$ plasmid form in $R$. felis strain LSU DNA provided by these authors, thus confirming their data [14]. Subsequently, we tested another $R$. felis strain, the RF2125 strain endemic in Archaeopsylla erinacei fleas from Algeria [22]. Although the pRF plasmid form was detected from $64 \mathrm{~A}$. erinacei, we failed to detect the $\mathrm{pRF} \delta$ plasmid form in any of these. Thus, in addition to culture conditions, the plasmid content of $R$. felis may vary from one strain to another. The former hypothesis is supported by the fact that the URRWX$\mathrm{Cal}_{2}{ }^{\mathrm{T}}$ strain may have one or two plasmid forms as demonstrated by our results, that the LSU strain, belonging to the same genotype, has one plasmid form [14], and that the

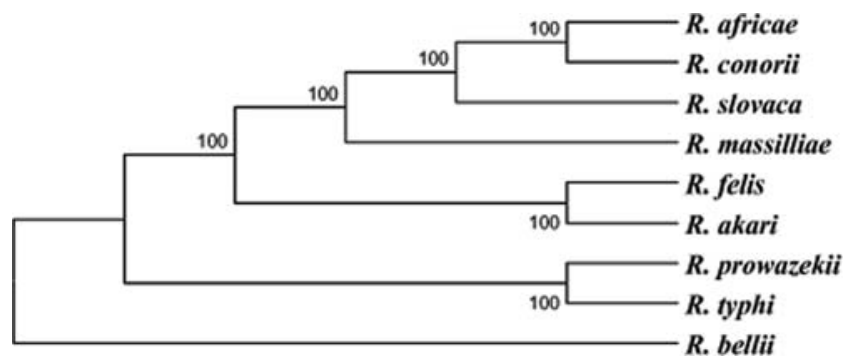

Figure 3. Determination of the $R$. felis plasmid ratio. The Southern blot obtained by hybridizing $R$. felis genomic DNA digested with Pvul and resolved by PFGE with probes specific for each plasmid form [18] was digitalized by transmission scanning (ImageScanner, Amersham Biosciences). The quantification of each labelled plasmid band was estimated by analysis with the ImageMaster 2D Platinium Version 6.0 software (Amersham Biosciences). The pRF and pRF $\delta$ spots represented $57 \%$ and $43 \%$, respectively, of the hybridization intensity. doi:10.1371/journal.pone.0002289.g003

RF2125 strain, genetically different from the other two strains (Table 2), may have one or no plasmid.

\section{Phylogeny of $R$. felis}

Using sequences from 15 chromosome-encoded proteins or from 21 conserved hypothetical proteins, Gillespie et al. proposed the creation of a fourth phylogenetic cluster within the Rickettsia genus, the "transitional group", that contained $R$. felis [14]. However, the data produced by these authors do not provide any evidence that $R$. felis belongs to "a lineage distinct from other previously established taxonomic categories for rickettsiae". As stated by the authors, their phylogenetic study is similar to other recently published rickettsial trees, which showed no evidence or need for the creation of a fourth lineage $[23,24]$. This result even contradicts a previous article by the same team where $R$. felis was clearly associated with the SFG [25]. Initial speculations on an intermediate status of $R$. felis, with phenotypic properties similar to $R$. typhi but a genetic clustering with spotted fever group rickettsiae, resulted from studies that have not been reproduced $[1,8-11,25,26]$. Moreover, the only strain recovered from this work was $R$. typhi and contamination was acknowledged in one of these four early papers [12]. By analysing ad hoc genes, one may also cluster $R$. felis and $R$. bellii because both species share unique characteristics among rickettsiae such as the largest chromosomes, or the presence of tra clusters and transposases [18,23].

Moreover, the analysis of various genes that provided reliable phylogenetic organisations of rickettsiae demonstrated that $R$. felis

Table 2. Genetic variability of $R$. felis strain URRWXCal ${ }_{2}^{\top}$ compared to other studied strains

\begin{tabular}{llll}
\hline Strain & LSU $^{\mathbf{a}}$ & LSU $^{\mathbf{b}}$ & $\begin{array}{l}\text { Algerian } A . \\
\text { erinacei strain }\end{array}$ \\
\hline URRWXCal $_{2}^{\top}$ & $D^{c, e}$ & $\mathrm{I}^{\mathrm{d}, \mathrm{e}}$ & $\mathrm{D}^{c, f}$ \\
\hline
\end{tabular}

a Sequences from the LSU strain were determined by Bouyer et al. [25];

${ }^{b}$ Sequences from the LSU strain were determined by Pornwiroon et al. [14];

${ }^{\mathrm{C}} \mathrm{D}$ = different genotype;

$\mathrm{d}$ I = Identical genotype;

$\mathrm{e}=$ ompA gene;

$\mathrm{f}=$ glt $A$ gene.

doi:10.1371/journal.pone.0002289.t002 


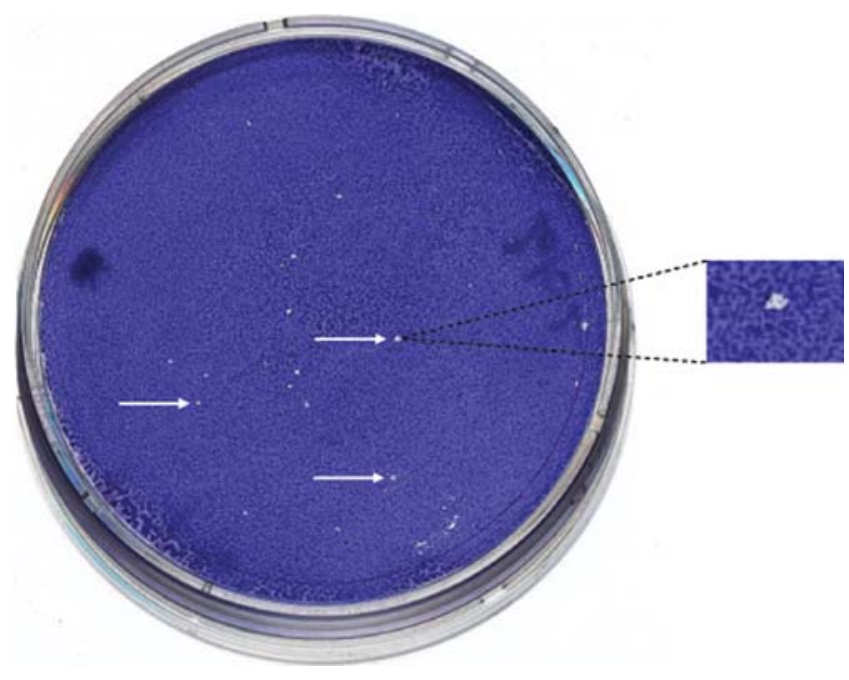

Figure 4. Phylogenetic tree inferred from the comparison of 667 concatenated Rickettsia core protein-coding genes using the maximum parsimony method. Bootstrap values are indicated at branch nodes. A similar topology was obtained using the NeighborJoining analysis method.

doi:10.1371/journal.pone.0002289.g004

was placed in a cluster also including $R$. akari and $R$. australis within the SFG [27-29]. As a matter of fact, $R$. australis is transmitted by ticks and has unambiguously been classified within the spotted fever group [30]. However, the reliability of phylogenetic studies based on selected genes may be impaired by a selection bias, in particular due to recombination or lateral gene transfer, as previously described for Rickettsia species [31]. In the most complete phylogenetic study of Rickettsia species performed to date, based on complete genome sequences, $R$. felis was clearly classified within the SFG [32]. Herein, with the same method as that used by Gillespie $e t$ $a l$. [19], the phylogenetic tree that we inferred from the comparison of 667 concatenated core genes of Rickettsia unambiguously placed $R$. felis within the SFG (Figure 4). Therefore, our data do not demonstrate any necessity to create a new cluster. In addition, the distance between $R$. felis and other SFG species is not bigger than that between $R$. helvetica, another SFG species, and other SFG members for example [28].

\section{Correlation host vector-phylotype}

The hypothesis that Rickettsia species have acquired virulence after the divergence of $R$. bellii and $R$. canadensis is misleading [19]. By omitting some data, one may build a simplified model of hostvector-rickettsia co-speciation, with $R$. prowazekii being associated with lice, $R$. felis with fleas and $R$. rickettsii with ticks, and subsequently determine which species is pathogenic or not. However, over the past 15 years, new data have contradicted this vision of rickettsiae [33]. As examples, $R$. parkeri, considered as non pathogenic for 65 years, was recently demonstrated to be a human pathogen [34]; $R$. canadensis is suspected epidemiologically and serologically to cause disease [35]; $R$. bellii has been shown to cause escharotic lesions when injected in guinea pigs [23] and may thus be pathogenic in humans. Finally, Coxiella burnetii (as $R$. diasporica), R. africae (as ESF agent), and Legionella pneumophila (as Tatlock agent) [36] were considered to be non-pathogenic rickettsiae in the past, before being recognized as human pathogens [33]. Recent findings demonstrated that the vector range of rickettsiae is not fully established [33]. For examples, $R$. prowazekii (a typical louse borne disease) was found in ticks in Africa and Mexico $[37,38]$ and was reported in lice and acarids from flying squirrels in the USA [39]. Similarly, $R$. conorii was reported to infect mites and lice [40,41], and $R$. bellii was found in insects (unpublished data), although both species were believed to be strictly associated with ticks. Therefore, a simplification of the relationship between ecological niche, pathogenicity and phylotype is not possible, and these findings forced rickettsiologists to define more carefully rickettsiae as either pathogenic or of unknown pathogenicity. Moreover, by deliberately omitting SFG rickettsiae of unknown pathogenicity (such as the SFG species $R$. montanensis) the authors proposed in their Figure 1 a biased representation of what is currently known about rickettsial pathogenicity [19].

\section{Discussion}

We were surprised that the only hypothesis produced by Gillespie et al. [19] to explain the discordance between our results, showing the presence of two plasmids in R. felis [18], and those of Pornwiroon et al. who could detect only one plasmid [14], was that the small plasmid form of $R$. felis was an artefact of our genome assembly. It is clear in other bacterial genera that the plasmid content may vary from one strain to another and that plasmids may not be stably maintained in culture $[42,43]$. In our previous work, we had shown the presence of the two plasmid forms [18], and demonstrated in the present article that $R$. felis may have one, two or no plasmid, depending on the strain or the culture passage history. This plasmidic instability, which we also identified in $R$. africae (unpublished data), was also described recently in $R$. peacockii [21]. This phenomenon poses the problem of the significance of the genomic sequences of rickettsiae passaged many times in cell culture prior to sequencing, such as $R$. prowazekii or $R$. conorii.

Regarding the phylogenetic position of $R$. felis, the choice of genes for infering phylogenies should be extremely careful. For example, Woese clearly demonstrated discrepancies between the phylogenies obtained using the ribosomal operon and amino-acyl -tRNA synthetases [44]. This is mainly due to the fact that bacteria have a core set of conserved and inherited genes, which may be used to establish phylogenies reflecting their true evolution, and a set of genes acquired by lateral gene transfer or recombination, which may provide biased phylogenies [45]. By selecting a set of specific genes, Gillespie et al. [19] proposed the creation of a specific phylogenetic position for $R$. felis, between SFG and TG rickettsiae, contradicting biological data and their own work [25]. Moreover, $R$. felis may be subject to gene recombination with $R$. typhi as these two rickettsiae can meet in the same host flea. However, the current position of $R$. felis and its clustering with $R$. australis and $R$. akari is exactly the same as that defined in as early as 1999 [46]. Herein, we performed a unique phylogenetic study of Rickettsia species based on the concatenation of their core gene set and demonstrated unambiguously that $R$. felis belongs to the spotted fever group. Finally, classification of rickettsiae based on current knowledge of host specificity is not reliable.

We also demonstrated for the first time using a cloning method in Vero cells that $R$. felis does not grow at $37^{\circ} \mathrm{C}$. This result confirms the fact that authors who initially reported a culture of this species at $37^{\circ} \mathrm{C}$ [8-11] did not grow the current strain of $R$. felis [47]. Their data may have resulted from a contamination with $R$. typhi, which they later acknowledged [12]. This also explains why phenotypic traits initially described for $R$. felis were similar to those of $R$. typhi [8-11].

We believe that it was important to clarify the status of $R$. felis. We clearly demonstrated that $R$. felis is a SFG rickettsia, that it 
does not grow at $37^{\circ} \mathrm{C}$ and that it has, without any possible doubt, two plasmids. Finally, we think that it would have been fair, since our $R$. felis strain is available, to check the presence of plasmids prior concluding that our data resulted from an error.

\section{Materials and Methods}

PCR detection of pRF and pRF $\delta$ plasmids

$R$. felis strain URRWXCal ${ }_{2}^{\mathrm{T}}$ kept frozen at $-80^{\circ} \mathrm{C}$ since initial isolation was cultivated in XTC2 cells as previously described [47]. DNA was extracted from freshly cultivated $R$. felis using the QIAmp Tissue kit (Qiagen, Hilden, Germany). The pRF $\delta$ plasmid was detected using the primers $\mathrm{pRFa}$ and $\mathrm{pRFd}$ (expected size 1,168 bp, Figure 1). The pRF plasmid was detected using the primer pairs pRFa-pRFb (expected size $159 \mathrm{bp}$ ) and pRFc-pRFd (expected size 1,342 bp, Figure 1b). We used two negative controls, i. e., sterile water and a PCR mix without DNA. The amplification conditions were as follows: $2.0 \mu \mathrm{L}$ of DNA was mixed with $0.1 \mu \mathrm{L}$ Platinum TaqDNA Pol High Fidelity polymerase (Invitrogen, Cergy, France), $2.5 \mu \mathrm{L}$ High Fidelity PCR Buffer 10X, $0.5 \mu \mathrm{L}$ of a $10 \mathrm{mM}$ dNTP mixture, $1 \mu \mathrm{L}$ of $50 \mathrm{mM} \mathrm{MgSO}_{4}, 0.5 \mu \mathrm{L}$ of each primer $(10 \mathrm{mM})$, and $17.9 \mu \mathrm{L}$ sterile water. Amplification conditions included an initial denaturation at $94^{\circ} \mathrm{C}$ for $2 \mathrm{~min}$ followed by 25 cycles comprised of $94^{\circ} \mathrm{C}$ for 30 sec., $55^{\circ} \mathrm{C}$ for 30 sec., and $68^{\circ} \mathrm{C}$ for $2 \mathrm{~min}$. PCR products were resolved in $1 \%$ agarose gels with ethidium bromide.

\section{Plasmid detection kit}

We prepared a kit that contained DNA from $R$. felis strain $\mathrm{URRWXCal}_{2}{ }^{\mathrm{T}}$ (DNA1), $R$. conorii strain Malish 7 (DNA2) and $R$. africae strain ESF-5 (DNA3) (Table 3) extracted using the QIAmp Tissue kit (Qiagen), and PCR primers. All reagents in this kit were anonymized. Primers $\mathrm{pRFa}, \mathrm{pRFb}, \mathrm{pRF}$, and $\mathrm{pRFd}$ were renamed B, C, D, and E, respectively (Figure 1b). The kit was sent to five independent expert laboratories worldwide, including laboratories located in the USA (laboratory L1), Switzerland (L2), Greece (L3), Spain (L4), and Japan (L5). In addition to the above-described DNA samples, each kit contained the primer pairs B-E specific for the pRF $\delta$ plasmid, B-C and D-E specific for the pRF plasmid (Figure 1b), and AF (5'-CGTATGGGTATTATGGTTGC-3')AR (5'-ATTGCAAAAAGTACAGTGAACA-3') specific for the citrate synthase $(g l t A)$-encoding gene. Each primer pair was tested on each of the three DNA specimens (Table 1). For each PCR assay, two negative controls were used, $i$. e., sterile water and a PCR mix without DNA. For the B-E, B-C and D-E PCR assays, the amplification conditions were similar to those described above. For the AF-AR PCR assay, the amplification conditions were the following: $5.0 \mu \mathrm{L}$ of DNA was mixed with $0.125 \mu \mathrm{L}$ HotstarTaq Polymerase (Qiagen), $2.5 \mu \mathrm{L}$ Buffer, $2.5 \mu \mathrm{L} \mathrm{dNTP,} 1 \mu \mathrm{L} \mathrm{MgCl}_{2}$, $0.5 \mu \mathrm{L}$ of each primer, and $13.0 \mu \mathrm{L}$ sterile water. Amplification conditions included an initial denaturation at $94^{\circ} \mathrm{C}$ for $15 \mathrm{~min}$ followed by 39 cycles comprised of $94^{\circ} \mathrm{C}$ for $1 \mathrm{~min}$., $54^{\circ} \mathrm{C}$ for 30 sec., and $72^{\circ} \mathrm{C}$ for $2 \mathrm{~min}$. The reaction was completed by a final elongation step at $72^{\circ} \mathrm{C}$ for $5 \mathrm{~min}$.

\section{References}

1. Adams JR, Schmidtmann ET, Azad AF (1990) Infection of colonized cat fleas, Ctenocephalides felis (Bouché), with a rickettsia-like microorganism. Am J Trop Med Hyg 43: 400-409.

2. Raoult D, La Scola B, Enea M, Fournier PE, Roux V, et al. (2001) A fleaassociated Rickettsia pathogenic for humans. Emerg Infect Dis 7: 73-81.

3. Zavala-Velazquez JE, Ruiz-Sosa JA, Sanchez-Elias RA, Becerra-Carmona G, Walker DH (2000) Rickettsia felis rickettsiosis in Yucatan. Lancet 356: 1079-1080.

4. Schriefer ME, SacciJB Jr, Dumler JS, Bullen MG, Azad AF (1994) Identification of a novel rickettsial infection in a patient diagnosed with murine typhus. J Clin Microbiol 32: 949-954.
Table 3. DNA specimens sent to expert laboratories

\begin{tabular}{|c|c|c|}
\hline $\begin{array}{l}\text { Anonymized } \\
\text { DNA label }\end{array}$ & Species & Strain \\
\hline DNA1 & R. felis & URRWXCal $_{2}^{\top}$ (ATCC VR1525) \\
\hline DNA2 & R. conorii & Malish $7^{\top}$ (ATCC VR613) \\
\hline DNA3 & R. africae & ESF- $5^{\top}$ \\
\hline
\end{tabular}

doi:10.1371/journal.pone.0002289.t003

\section{Variation of plasmid content in $R$. felis}

K. Macaluso provided the expert laboratory L1 with DNA from five $R$. felis-positive (strain LSU) C. felis fleas [14]. This DNA was tested using the four above-described primer pairs and PCR conditions. We also tested 64 Archaeopsylla erinacei fleas from Algeria previously found to contain $R$. felis strain Rf2125 [22].

Detection of $\mathrm{pRF}$ and $\mathrm{pRF} \delta$ plasmids in single $R$. felis cells

Using tenfold dilutions of a suspension containing $10^{4}$ plaque forming units of $R$. felis strain URRWXCal ${ }_{2}{ }^{\mathrm{T}}$ (40 cell culture passages since initial isolation), we inoculated Vero cells at $30^{\circ} \mathrm{C}$ and $37^{\circ} \mathrm{C}$ and performed a plaque assay as previously described [48]. Then, we collected individually $20 \mathrm{R}$. felis clones grown from single $R$. felis cells (Figure 2). DNA extraction from each clone, and plasmid detection, were performed as described above. As positive control, we used DNA extracted from our current $R$. felis strain URRWXCal ${ }_{2}{ }^{\mathrm{T}}$ culture $(50$ cell culture passages)

\section{Phylogenetic analysis}

To estimate the phylogenetic position of $R$. felis among Rickettsia species, we based our analysis on the 704 core protein-coding genes identified by Blanc et al. by comparison of 7 rickettsial genomes [32]. Of these genes, a total of 667 complete orthologous genes were found using the Blast software in the $R$. slovaca and $R$. akari genomes [49]. Subsequently, the amino acid sequences of these 667 proteins were concatenated for each genome and multiple alignment was performed using the Mafft software [50]. Gapped positions were removed. The maximum parsimony and neighbor joining trees were constructed using the MEGA 3.1 software [51]. Branching support was evaluated using the bootstrap method.

\section{Author Contributions}

Conceived and designed the experiments: PF DR. Performed the experiments: PF GR GG KE AR FG MO APsaroulaki APortillo IB JO LB. Analyzed the data: PF CR GG DR KE AR FG MO APsaroulaki APortillo IB JO LB. Contributed reagents/materials/analysis tools: CR KE FC LB. Wrote the paper: PF GG DR AR MO APsaroulaki APortillo IB JO.

5. Richter J, Fournier PE, Petridou J, Häussinger D, Raoult D (2002) Rickettsia felis infection acquired in Europe and documented by Polymerase Chain Reaction. Emerg Infect Dis 8: 207-208.

6. Parola P, Miller RS, McDaniel P, Telford SR III, Rolain JM, et al. (2003) Emerging rickettsioses of the Thai-Myanmar border. Emerg Infect Dis 9: 592-595.

7. Azad AF, Sacci JB, Nelson WM, Dasch GA, Schmidtmann ET, et al. (1992) Genetic characterization and transovarial transmission of a typhus-like rickettsia found in cat fleas. Proc Natl Acad Sci USA 89: 43-46. 
8. Higgins JA, Radulovic S, Schriefer ME, Azad AF (1996) Rickettsia felis : a new species of pathogenic rickettsia isolated from cat fleas. J Clin Microbiol 34: 671-674.

9. Radulovic S, Higgins JA, Jaworski DC, Dasch GA, Azad AF (1995) Isolation, cultivation, and partial characterization of the ELB agent associated with cat fleas. Infect Immun 63: 4826-4829.

10. Radulovic S, Higgins JA, Jaworski DC, Azad AF (1995) In vitro and in vivo antibiotic susceptibilities of ELB rickettsiae. Antimicrob Agents Chemother 39: 2564-2566.

11. Azad AF, Radulovic S, Higgins JA, Noden BH, Troyer JM (1997) Flea-borne rickettsioses : ecologic considerations. Emerg Infect Dis 3: 319-327.

12. Radulovic S, Higgins JA, Jaworski DC, Azad AF (1996) Erratum to "In vitro and in vivo antibiotic susceptibilities of ELB rickettsiae". Antimicrob Agents Chemother 40: 2912

13. Noden BH, Radulovic S, Higgins JA, Azad AF (1998) Molecular identification of Rickettsia typhi and R.felis in co-infected Ctenocephalides felis (Siphonaptera: Pulicidae). J Med Entomol 35: 410-414.

14. Pornwiroon W, Pourciau SS, Foil LD, Macaluso KR (2006) Rickettsia felis from cat fleas: isolation and culture in a tick-derived cell line. Appl Environ Microbiol 72: 5589-5595.

15. Horta MC, Labruna MB, Durigon EL, Schumaker TT (2006) Isolation of Rickettsia felis in the mosquito cell line C6/36. Appl Environ Microbiol 72: 1705-1707.

16. Rolain JM, Sthul L, Maurin M, Raoult D (2002) Evaluation of antibiotic susceptibilities of three Rickettsial species including Rickettsia felis by a quantitative PCR DNA assay. Antimicrob Agents Chemother 46: 2747-2751.

17. Fang R, Raoult D (2003) Antigenic classification of Rickettsia felis by using monoclonal and polyclonal antibodies. Clin Diagn Lab Immunol 10: 221-228.

18. Ogata H, Renesto P, Audic S, Robert C, Blanc G, et al. (2005) The Genome Sequence of Rickettsia felis Identifies the First Putative Conjugative Plasmid in an Obligate Intracellular Parasite. PLoS Biol 3: e248.

19. Gillespie JJ, Beier MS, Rahman MS, Ammerman NC, Shallom JM, et al. (2007) Plasmids and Rickettsial Evolution: Insight from Rickettsia felis. PLoS ONE 2: e266.

20. Henderson G, Foil LD (1993) Efficacy of diflubenzuron in simulated household and yard conditions against the cat flea Ctenocephalides felis (Bouche) (Siphonoptera: Pulicidae). J Med Entomol 30: 619-621.

21. Baldridge GD, Burkhardt NY, Felsheim RF, Kurtti TJ, Munderloh UG (2007) Plasmids of the $\mathrm{pRM} / \mathrm{pRF}$ Family Occur in Diverse Rickettsia species. Appl Environ Microbiol.

22. Bitam I, Parola P, De La Cruz KD, Matsumoto K, Baziz B, et al. (2006) First molecular detection of Rickettsia felis in fleas from Algeria. Am J Trop Med Hyg 74: 532-535.

23. Ogata H, La Scola B, Audic S, Renesto P, Blanc G, et al. (2006) Genome Sequence of Rickettsia bellii Illuminates the Role of Amoebae in Gene Exchanges between Intracellular Pathogens. PLoS Genet 2: e76.

24. Abergel C, Blanc G, Monchois V, Renesto P, Sigoillot C, et al. (2006) Impact of the excision of an ancient repeat insertion on Rickettsia conorii guanylate kinase activity. Mol Biol Evol 23: 2112-2122.

25. Bouyer DH, Stenos J, Crocquet-Valdes P, Moron C, Vsevolod P, et al. (2001) Rickettsia felis : molecular characterization of a new member of the spotted fever group. Int J Syst Evol Microbiol 51: 339-347.

26. Higgins JA, Sacci JB, Schriefer ME, Endris RG, Azad AF (1994) Molecular identification of rickettsia-like microorganisms associated with colonized cat fleas (Ctenocephalides felis). Insect Molecular Biology 3: 27-33.

27. Sekeyova Z, Roux V, Raoult D (2001) Phylogeny of Rickettsia spp. inferred by comparing sequences of 'gene D', which encodes an intracytoplasmic protein. Int J Syst Evol Microbiol 51: 1353-1360.

28. Ngwamidiba M, Blanc G, Raoult D, Fournier PE (2006) Scal, a previously undescribed paralog from autotransporter protein-encoding genes in Rickettsiaspecies. BMC Microbiol 6: 12.

29. Fournier PE, Raoult D (2007) Bacteriology, taxonomy, and phylogeny of Rickettsia. In: Raoult D, Parola P, eds. Rickettsial diseases. New York: Informa healthcare. pp 1-13.
30. Stenos J, Walker DH (2000) The rickettsial outer-membrane protein A and B genes of Rickettsia australis divergent rickettsia of the spotted fever group. Int J Syst Evol Microbiol 50: 1775-1779.

31. Wolf YI, Aravind L, Koonin EV (1999) Rickettsiae and Chlamydiae evidence of horizontal gene tranfer and gene exchange. Trends Genet 15: 173-175.

32. Blanc G, Ogata H, Robert G, Audic S, Suhre K, et al. (2007) Reductive genome evolution from the mother of Rickettsia. PLOS Genet 3: e14.

33. Parola P, Paddock CD, Raoult D (2005) Tick-borne rickettsioses around the world: emerging diseases challenging old concepts. Clin Microbiol Rev 18: 719-756.

34. Paddock CD, Sumner JW, Comer JA, Zaki SR, Goldsmith CS, et al. (2004) Rickettsia parkeri: a newly recognized cause of spotted fever rickettsiosis in the United States. Clin Infect Dis 15: 805-811.

35. Bozeman FM, Elisberg BL, Humphries JW, Runcik K, Palmer DB Jr (1970) Serologic evidence of Rickettsia canada infection of man. J Infect Dis 121: 367-371.

36. Hebert GA, Moss CW, McDougal LK, Bozeman FM, McKinney RM, et al. (1980) The rickettsia-like organisms TATLOCK (1943) and HEBA (1959): bacteria phenotypically similar to but genetically distinct from Legionella pneumophila and the WIGA bacterium. Ann Med Inter 92: 45-52.

37. Medina-Sanchez A, Bouyer DH, cantara-Rodriguez V, Mafra C, ZavalaCastro J, et al. (2005) Detection of a typhus group Rickettsia in Amblyomma ticks in the state of Nuevo Leon, Mexico. Ann N Y Acad Sci 1063: 327-332.

38. Reiss-Gutfreund RJ (1966) The isolation of Rickettsia prowazeki and mooseri from unusual sources. Am J Trop Med Hyg 15: 943-949.

39. Bozeman FM, Masiello SA, Williams MS, Elisberg BL (1975) Epidemic typhus rickettsiae isolated from flying squirrels. Nature 255: 545-547.

40. Houhamdi L, Raoult D (2006) Experimentally infected human body lice (Pediculus humanus humanus) as vectors of Rickettsia rickettsii and Rickettsia conorii in a rabbit model. Am J Trop Med Hyg 74: 521-525.

41. Choi YJ, Lee EM, Park JM, Lee KM, Han SH, et al. (2007) Molecular detection of various rickettsiae in mites (acari: trombiculidae) in southern Jeolla Province, Korea. Microbiol Immunol 51: 307-312.

42. Welch RA, Burland V, Plunkett G III, Redford P, Roesch P, et al. (2002) Extensive mosaic structure revealed by the complete genome sequence of uropathogenic Escherichia coli. Proc Natl Acad Sci U S A 99: 17020-17024.

43. Deng W, Burland V, Plunkett G III, Boutin A, Mayhew GF, et al. (2002) Genome sequence of Yersinia pestis KIM. J Bacteriol 184: 4601-4611.

44. Woese GR, Olsen GJ, Ibba M, Söll D (2000) Aminoacyl-tRNA synthetases, the genetic code, and the evolutionary process. Microbiol Mol Biol Rev 64: 202-236.

45. Tettelin H, Masignani V, Cieslewicz MJ, Donati C, Medini D, et al. (2005) Genome analysis of multiple pathogenic isolates of Streptococcus agalactiae: implications for the microbial "pan-genome". Proc Natl Acad Sci U S A 102: $13950-13955$.

46. Roux V (1999) Phylogenetic analysis and taxonomic relationships among the genus Rickettsia. In: Raoult D, Brouqui P, eds. Rickettsiae and Rickettsial diseases at the turn of the third millinium. Marseille: Elsevier. pp 52-66.

47. La Scola B, Meconi S, Fenollar F, Rolain JM, Roux V, et al. (2002) Emended description of Rickettsia felis (Bouyer et al. 2001) a temperature-dependant cultured bacterium. Int J Syst Evol Microbiol 52: 2035-2041.

48. Rolain JM, Maurin M, Vestris G, Raoult D (1998) In vitro susceptibilities of 27 rickettsiae to 13 antimicrobials. Antimicrob Agents Chemother 42: 1537-1541.

49. Altschul SF, Madden TL, Schaffer AA, Zhang J, Zhang Z, et al. (1997) Gapped BLAST and PSI-BLAST: a new generation of protein database search programs. Nucleic Acids Res 25: 3389-3402.

50. Katoh K, Misawa K, Kuma K, Miyata T (2002) MAFFT: a novel method for rapid multiple sequence alignment based on fast Fourier transform. Nucleic Acids Res 30: 3059-3066.

51. Kumar S, Tamura K, Nei M (2004) MEGA3: Integrated software for Molecular Evolutionary Genetics Analysis and sequence alignment. Brief Bioinform 5: 150-163. 